\title{
Hsa-miR-125a-3p and hsa-miR-125a-5p are downregulated in non-small cell lung cancer and have inverse effects on invasion and migration of lung cancer cells
}

\author{
Lili Jiang 1,2, Qin Huang 1,2, Siyang Zhang33, Qingfu Zhang 1,2, Jihong Chang 1,2, Xueshan Qiu*1,2 and Enhua Wang 1,2
}

\begin{abstract}
Background: Two mature microRNAs (miRNAs), hsa-miR-125a-3p and hsa-miR-125a-5p (collectively referred to as hsamiR-125a-3p/5p), are derived from 3' and 5' ends of pre-miR-125a, respectively. Although impaired regulation of hsamiR-125a-5p has been observed in some tumors, the role of this miRNA in invasion and metastasis remains unclear, and few studies have examined the function of hsa-miR-125a-3p. In order to characterize the functions of hsa-miR$125 a-3 p / 5 p$ in invasion and metastasis of non-small cell lung cancer (NSCLC), we investigated the relationships between hsa-miR-125a-3p/5p expression and lymph node metastasis in NSCLC tissues. We also explored the impact of expression of these miRNAs on invasive and migratory capabilities of lung cancer cells.

Methods: Expression of hsa-miR-125a-3p/5p in NSCLC tissues was explored using real-time PCR. The relationships between hsa-miR-125a-3p/5p expression and pathological stage or lymph node metastasis were assessed using the Spearman correlation test. For in vitro studies, lung cancer cells were transfected with sense and antisense 2'-O-methyl oligonucleotides for gain-of-function and loss-of-function experiments. Transwell experiments were performed to evaluate cellular migration and invasion.

Results: Expression of hsa-miR-125a-3p/5p was lower in NSCLC tissues than in adjacent normal lung tissues (LAC). Furthermore, the results from the Spearman correlation test showed a negative relationship between hsa-miR-125a-3p expression and pathological stage or lymph node metastasis and an inverse relationship between hsa-miR-125a-5p expression and pathological stage or lymph node metastasis. In vitro gain-of-function experiments indicated that hsamiR-125a-3p and hsa-miR-125a-5p function in an opposing manner, suppressing or enhancing cell migration and invasion in A549 and SPC-A-1 cell lines, respectively. These opposing functions were further validated by suppression of hsa-miR-125a-3p and hsa-miR-125a-5p expression in loss-of-function experiments.

Conclusion: Hsa-miR-125a-3p and hsa-miR-125a-5p play distinct roles in regulation of invasive and metastatic capabilities of lung cancer cells, consistent with the opposing correlations between the expression of these miRNAs and lymph node metastasis in NSCLC. These results provide new insights into the roles of miR-125a family members in the development of NSCLC.
\end{abstract}

\section{Background}

MicroRNAs (miRNAs) are a class of endogenous, noncoding RNAs, approximately 20-24 nucleotides in length,

\footnotetext{
* Correspondence: qiuxues@hotmail.com

1 Department of Pathology, the First Affiliated Hospital of China Medical University, No. 92 North Second Road, Heping District, Shenyang, Liaoning 110001, China

Full list of author information is available at the end of the article
}

that are derived from longer transcripts termed pri-miRNAs and pre-miRNAs [1-5]. MiRNAs recognize target mRNAs through partial complementarity to specific sequences within the mRNAs and posttranscriptionally regulate gene expression in multicellular organisms [6-9]. Emerging evidence has shown that human miRNA genes are frequently located in cancer-associated genomic 
regions, and perturbed miRNA expression patterns have been detected in many human cancers [10]. Therefore, it is of utmost importance to further elucidate the biological functions of miRNAs.

Recently, miRNAs have been shown to play a role in invasion and metastasis [11-15]. For example, miR-155 may play an important role in the TGF- $\beta$-induced epithelial-mesenchymal transition (EMT) and in cell migration and invasion through targeting of the RhoA transcript [16]. MiR-21 has been shown to stimulate cell invasion and metastasis in several tumor models, including breast cancer [12], colon cancer [17], and glioma [18]. MiR-10b can be activated by the pro-metastatic transcription factor TWIST1 and is essential for TWIST1-induced EMT involved in promotion of cell motility and invasiveness [19]. Tumor invasion and metastasis are the critical steps that define the prognosis of cancer patients. Therefore, understanding the specific roles of miRNAs in cancer progression could lead to the identification of predictive markers and the development of novel therapeutic strategies for patients with metastases.

MiR-125a is one of the many miRNAs that remain to be fully characterized. Using miRNA microarray analysis, Yanainhara and colleagues [20] found that miR-125a, specifically the hsa-miR-125a-5p mature miRNA, is located at $19 \mathrm{q} 13.41$ and that its expression is downregulated in NSCLC. Recently, a new member of the mature miR-125a family has been identified and named hsa-miR-125a-3p. Unfortunately, the expression and function of hsa-miR125a-3p are currently unknown. In this study, we found that expression of both hsa-miR-125a-5p and hsa-miR$125 a-3 p$ is decreased significantly in NSCLC tissues in comparison to LAC tissues. Changes in expression of both hsa-miR-125a-3p and hsa-miR-125a-5p are associated with pathological stage and lymph node metastasis in lung cancer, but in an opposing manner as shown by the Spearman correlation test. In cellular studies, hsamiR-125a-3p and hsa-miR-125a-5p also appeared to function in opposing manners in lung cancer cells, suppressing or enhancing cell migration and invasion, respectively. These results identify a potential role for the miR-125a family in metastasis of NSCLC.

\section{Methods}

\section{Samples}

We analyzed 52 pairs of non-small cell lung cancer specimens and corresponding normal lung tissues (LAC) collected at the time of surgery and prior to chemotherapy. Specimens were obtained from patients at the First Affiliated Hospital of China Medical University from 1 January 2006 to 1 December 2007 with informed consent. For the majority of samples, clinical and biological information was available. The study has been approved by the Hospitals' Ethical Review Committee.

\section{Cell culture}

The HBE (Human Bronchiolar Epithelium) cell line and the human lung cancer cell lines SPC-A-1 (adenocarcinoma), LH7 and NCI-H460 (large cell cancinoma) were propagated in RPMI1640 (Gibco). The A549 (adenocarcinoma) cell line was propagated in Dulbecco's Modifed Eagle Medium (Gibco). In both cases, the medium was supplemented with $10 \%$ fetal bovine serum (FBS), $100 \mathrm{U} /$ $\mathrm{ml}$ penicillin, and $100 \mathrm{U} / \mathrm{ml}$ streptomycin. Cells were cultured at $37^{\circ} \mathrm{C}$ in $5 \% \mathrm{CO}_{2}$ until they reached a confluency of $75 \%$.

\section{Transfection}

Depletion of hsa-miR-125a-3p/5p in the A549 and SPCA-1 cell lines was achieved through transfection with antisense 2'-O-methyl oligonucleotides directed against hsa-miR-125a-3p/5p. Cells were transfected using Lipofetamine $^{\text {tax }} 2000$ (Invitrogen) according to the manufacturer's protocol.

Briefly, complexes containing the oligonucleotides were prepared according to the recommended protocol and added directly to cells at a final oligonucleotide concentration of $0.4 \mathrm{nmol} / \mathrm{mL}$. Oligonucleotides composed entirely of 2'-O-methyl bases were chemically synthesized by Integrated DNA Technologies (GeneChem) and were comprised of the following sequences: 2'-O-Mesense-3p: 5'-ACA GGU GAG GUU CUU GGG AGCC-3' 2'-O-Me-antisense-3p: 5'-GGC UCC CAA GAA CC U CAC CUGU-3', 2'-O-Me-scramble-3p: 5'-GGU CGG UGC UCG AUG CAG GUAA-3', 2'-O-Me-sense-5p: 5'UCC CUG AGA CCC UUU AAC CUG UGA-3', 2'-OMe-antisense- 5p: 5'-UCA CAG GUU AAA GGG UCU CAG GGA-3', 2'-O-Me-scramble-5p: 5'-GGA CG G CGA UCA GAU AAG AGU UCU-3'. Cells were divided into four groups: an untreated group incubated only in the normal media (untreated), a group transfected with the scrambled 2'-O-methyl oligonucleotide (scramble); a group transfected with the sense 2'-O-methyl oligonucleotide (sense) and a group transfected with the antisense 2'-O-methyl oligonucleotide (antisense). The untreated and scramble groups served as negative controls.

\section{Quantitative real-time polymerase chain reaction (qRT- PCR)}

Expression of mature miRNAs was assayed using the TaqMan MicroRNA Assay in accordance with the manufacturer's instructions (Applied Biosystems). All reactions, including no-template controls and RT-minus controls, were run in an ABI Prism 7900HT Sequence detection system (Applied Biosystems). Specific RT primers and TaqMan probes were used to quantify the expression of hsa-miR-125a-3p (PN: 4395310) and hsa-miR125a-5p (PN: 4395309). Samples were normalized to RNU6B (PN: 4373381) or U18 (PN: 4380904) as indi- 
cated. For quantification of tissue samples, RT-PCR analysis was performed in two independent experiments, each using two independent samples. For quantification of cell samples, RT-PCR analysis was performed in three independent experiments, each using three independent samples. MiRNA expression data is presented as fold difference relative to either RNU6B or U18 based on the following equation: $R Q=2^{-\Delta \Delta C t}$.

\section{Cell migration assays}

For cell migration assays, $5 \times 10^{4}$ cells were trypsinized, washed, resuspended in serum-free RPMI1640 or DMEM, and placed in the top portion of the chamber. The lower portion of the chamber contained 10\% FBS for use as a chemoattractant. The chambers were incubated at $37^{\circ} \mathrm{C}$ in $5 \% \mathrm{CO}_{2}$ for $24 \mathrm{~h}$, washed with PBS, and fixed in $100 \%$ methanol. Following fixation, cells were stained with Haematoxylin and imaged, and the number of migrating cells was counted. Five random fields were analyzed for each chamber. Assays were conducted in duplicate in three independent experiments.

\section{Cell invasion assays}

Pre-chilled serum-free RPMI1640 or DMEM was mixed with Matrigel (1:7; BD Biosciences). The upper compartments of the chambers were filled with $100 \mu 1$ of the mixture, and the Matrigel was allowed to solidify at room temperature for $4 \mathrm{~h}$. After solidification, $5 \times 10^{4}$ cells were trypsinized, washed, resuspended in serum-free RPMI1640 or DMEM, and placed in the top portion of the chamber. The lower portion of the chamber contained $10 \%$ FBS for use as a chemoattractant. The chambers were incubated at $37^{\circ} \mathrm{C}$ in $5 \% \mathrm{CO}_{2}$ for $24 \mathrm{~h}$, washed with PBS, and fixed in $100 \%$ methanol. Fixed cells were stained with Haematoxylin and imaged, and the number of invasive cells was counted. Five random fields were analyzed for each chamber. Assays were conducted in duplicate in three independent experiments.

\section{Statistical analysis}

The SPSS 13.0 statistical software package was used for all analyses. For real-time PCR data, the statistical analysis of hsa-miR-125a-3p/5p expression levels in NSCLC tissues and corresponding LAC tissues was $\log 2$ transformed. Paired-samples T-test was used to analyze significant differences in hsa-miR-125a-3p/5p expression between NSCLC and LAC tissues. All values are expressed as mean $\pm \mathrm{SD}$. The Chi-square test was used to determine the relationship between hsa-miR-125a-3p/5p expression and clinicopathological variables. The twosided Fisher's exact test to determine the relationship between hsa-miR-125a-3p/5p expression and clinico- pathological variables when the number of tumors analyzed was less than 5 [21]. The Mann-Whitney test was used for pathological grade and clinical stage ranked data analysis. Spearman correlation analysis was used to determine the correlation between hsa-miR-125a-3p/5p expression and clinical stage and lymph node metastasis status. Other results were analyzed using independent samples T-test. Results were considered to be statistically significant at values of $\mathrm{p}<0.05$.

\section{Results}

\section{Downregulation of hsa-miR-125a-3p/-5p expression in NSCLC tissues}

Although it has been observed that expression of hsamiR-125a-5p is downregulated in NSCLC using miRNA microarray analysis, expression levels of hsa-miR-125a$3 p$ in NSCLC remain unknown. Therefore, we examined the relative expression of hsa-miR-125a-3p and hsa-miR125a-5p in 52 NSCLCs and paired LACs by real-time PCR. Expression of RNU6B was used as an internal standard. Expression of hsa-miR-125a-3p/5p decreased in NSCLCs in comparison to matched LACs $(\mathrm{p}<0.05$, AUC-3p $=0.735$, AUC-5p = 0.845, Fig 1 and Fig 2, Additional file 1). The mean expression levels of hsa-miR125a-3p in NSCLCs was decreased approximate 4.5 folds of that in LACs ( $<<0.001$, Fig 3A) and hsa-miR-125a-5p was decreased approximate 6 folds $(\mathrm{p}<0.001$, Fig $3 \mathrm{~B})$.

\section{Correlation between hsa-miR-125a-3p/5p expression and clinicopathological variables of NSCLC}

To determine the effects of hsa-miR-125a-3p/5p expression on tumor initiation and progression, lung cancer patients were divided into two groups based on the mean level of hsa-miR-125a-3p and hsa-miR-125a-5p expression in 52 NSCLCs. The two groups were defined as follows: hsa-miR-125a-3p low expression and high expression (1.2352 of the $\log 2$ value) and hsa-miR-125a$5 \mathrm{p}$ low expression and high expression (1.8594 of the $\log 2$ value) [22]. The relationships between hsa-miR-125a-3p/ $5 p$ expression and clinicopathological variables for lung cancer are shown in Table 1 and Table 2 . Statistically significant associations between hsa-miR-125a-3p and hsamiR-125a-5p expression and pathological stage were observed $(\mathrm{p}=0.012$ and $\mathrm{p}=0.002$, respectively, MannWhitney Test). Changes in expression of hsa-miR-125a$3 p$ and hsa-miR-125a-5p were also statistically significantly associated with lymph node metastasis in lung cancer $(\mathrm{p}=0.034$ and $\mathrm{p}=0.042$, respectively, Two-sided Fisher's Exact Test). No correlation was observed between hsa-miR-125a-3p/5p expression and gender, histology type, or pathological grade. However, the hsa-miR$125 \mathrm{a}-3 \mathrm{p}$ expression level was correlated with age $(\mathrm{p}=$ 


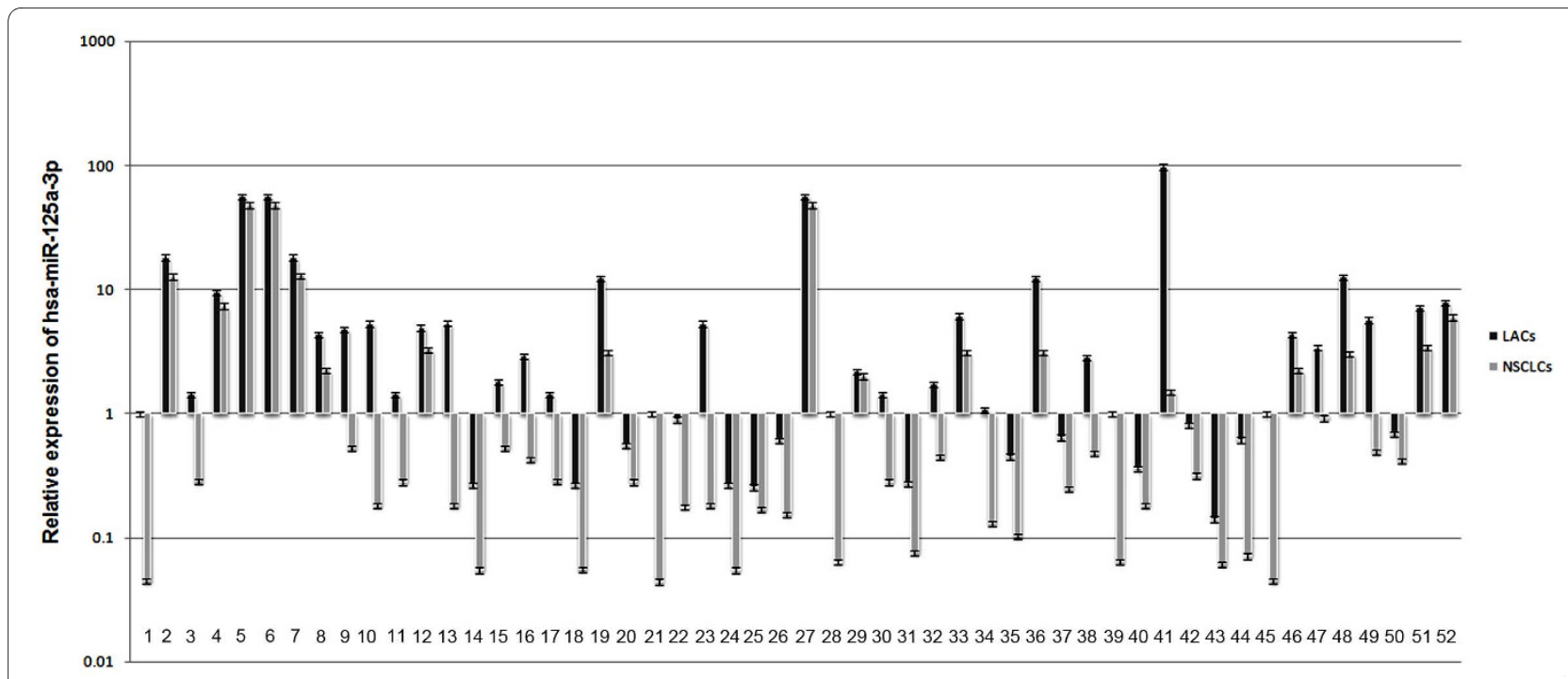

Figure 1 Relative expression of hsa-miR-125a-3p in lung cancer tissues. The relative expression of hsa-miR-125a-3p decreased in 52 NSCLCs in comparison to corresponding LACs. The data are representative of three independent experiments, and the relative expression values were calculated using the equation $R Q=2^{-\Delta \Delta C t}$.

0.031 , Chi-square Test), in contrast to that of hsa-miR$125 \mathrm{a}-5 \mathrm{p}$.

In order to better characterize the relationship between hsa-miR-125a-3p/5p expression and pathological stage and lymph node metastasis, we further analyzed the pathological stage and lymph node metastasis data using the Spearman correlation test. The results showed a negative correlation between hsa-miR-125a-3p expression and pathological stage $(\mathrm{r}=-0.352, \mathrm{p}=0.011)$, as well as lymph node metastasis $(\mathrm{r}=-0.326, \mathrm{p}=0.018)$. However, the correlations between hsa-miR-125a-5p expression and pathological stage $(\mathrm{r}=0.439, \mathrm{p}=0.001)$ and lymph node metastasis $(\mathrm{r}=0.300, \mathrm{p}=0.031)$ were positive.

\section{Predicted and confirmed mRNA targets}

Results from tissue expression analysis indicated that hsamiR-125a-3p and hsa-miR-125a-5p are associated with metastasis. Thus, we used computational analysis to predict metastasis-related target mRNAs of hsa-miR-125a$3 \mathrm{p}$ and hsa-miR-125a-5p. The analysis was conducted using microrna.org and the TargetScanHuman 5.1 and MiRBase webservers. Target predictions from

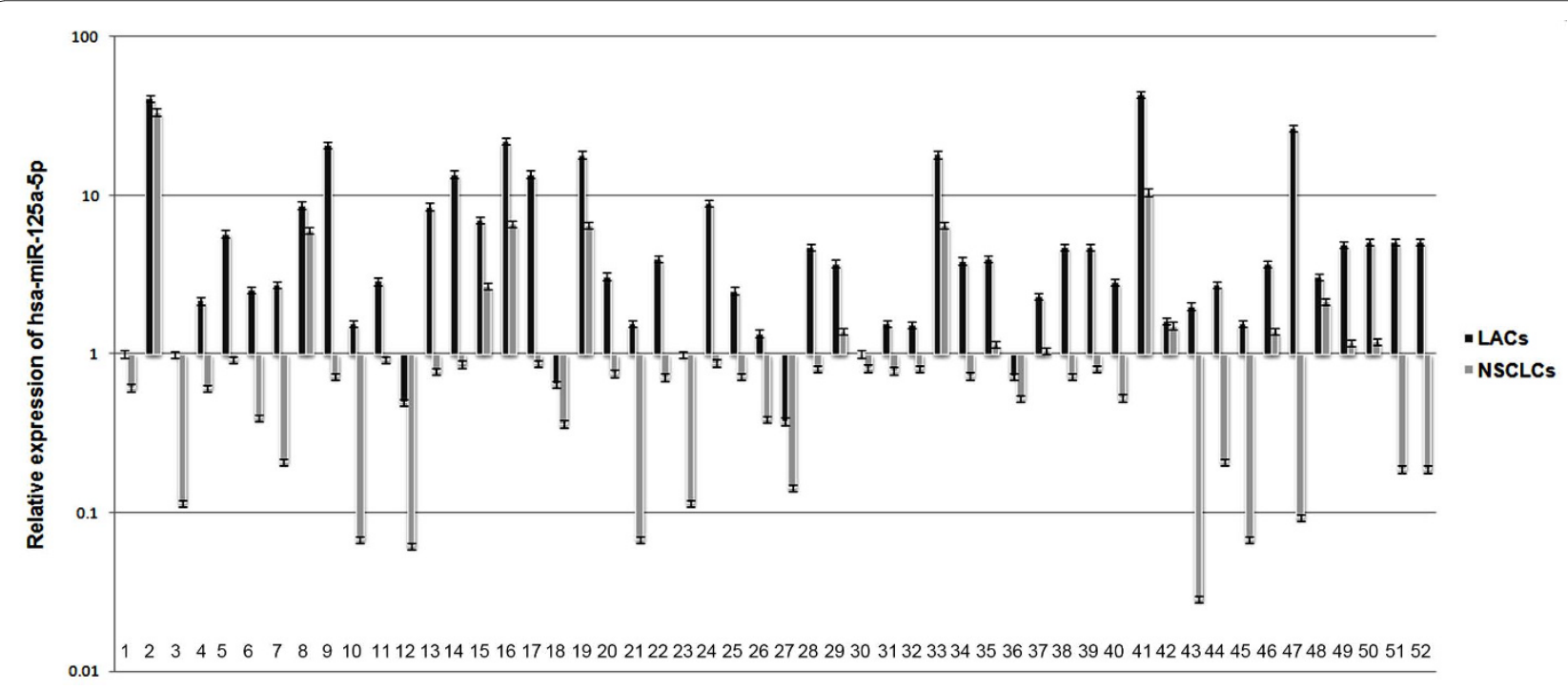

Figure 2 Relative expression of hsa-miR-125a-5p in lung cancer tissues. The relative expression of hsa-miR-125a-5p decreased in 52 NSCLCs in comparison to corresponding LACs. The results are representative of three independent experiments, and the relative expression values were calculated using the equation $\mathrm{RQ}=2^{-\Delta \Delta \mathrm{Ct}}$. 


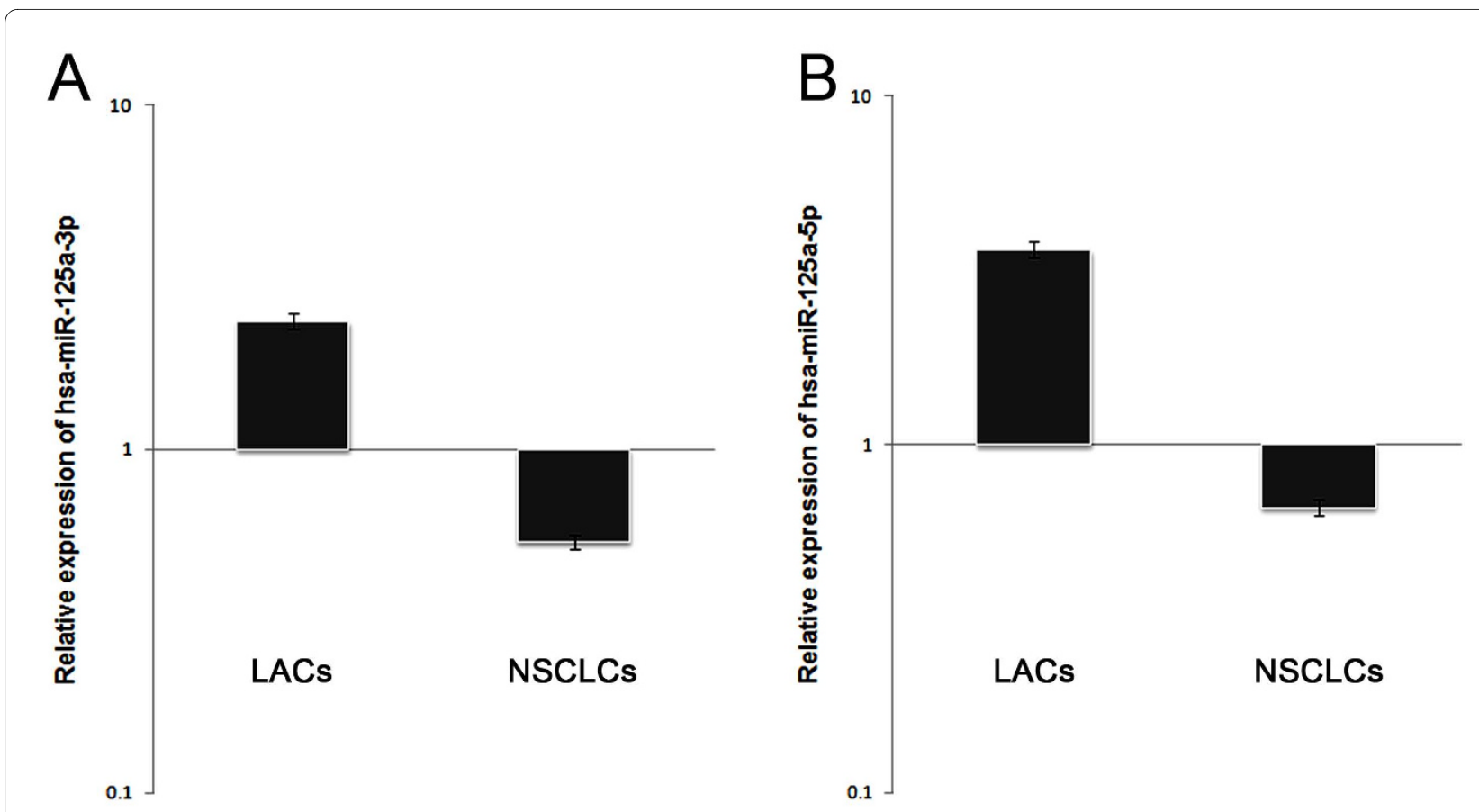

Figure 3 Mean levels of hsa-miR-125a-3p and hsa-miR-125a-5p in lung cancer tissues. (A) The mean level of hsa-miR-125a-3p relative expression in 52 NSCLCs. (B) The mean level of hsa-miR-125a-5p relative expression in 52 NSCLCs. The values represent the means of three replicates, and the relative expression values were calculated using the equation $R Q=2^{-\Delta \Delta C t}$.

Microrna.org and MiRBase are based on the miRanda algorithm. TargetScanHuman5.1 utilized the TargetScan algorithm. The relationships between hsa-miR-125a-3p/ $5 \mathrm{p}$ and their potential target genes identified from these three databases are shown in Fig.4, Additional file 2, and Additional file 3. The details of these target genes are shown in Additional file 4 and Additional file 5.

\section{Downregulation of hsa-miR-125a-3p/5p expression in NSCLC cell lines}

In order to identify suitable cell lines for further studies, we examined the relative expression levels of hsa-miR125a-3p/5p in four lung cancer cell lines (LH7, A549, SPC-A-1, and NCI-H460). Expression of hsa-miR-125a$3 \mathrm{p} / 5 \mathrm{p}$ in the lung cancer cell lines was normalized to that of a control human bronchiolar epithelium (HBE) cell line. U18 was used as an internal standard for real-time PCR. We found that the expression levels of hsa-miR125a-3p and hsa-miR-125a-5p were lower in each of the four lung cancer cell lines than in the HBE cell line. The mean level of hsa-miR-125a-3p expression was moderately decreased in A549 cells ( $p<0.001$, Fig 5A), and the mean level of hsa-miR-125a-5p expression was moderately decreased in SPC-A-1 cells ( $<<0.001$, Fig 5B). Therefore, we chose the A549 cell line for further studies regarding hsa-miR-125a-3p and the SPC-A-1 cell line for further studies regarding hsa-miR-125a-5p.
Effects of gain-of-function of hsa-miR-125a-3p/5p on migratory and invasive capabilities of A549 and SPC-A-1 cells

To determine whether hsa-miR-125a-3p and hsa-miR$125 \mathrm{a}-5 \mathrm{p}$ are associated with migration and invasion in lung cancer cells, we adopted a gain-of-function approach. The quantities of hsa-miR-125a-3p/5p were exogenously increased by transfection of sense 2'-Omethyl oligonucleotides into A549/SPC-A-1 cells. We first utilized real-time PCR to analyze the expression of hsa-miR-125a-3p/5p to ensure that transfection with sense 2'-O-methyl oligonucleotides increased its expression after 24 hours. Expression in transfected cells was normalized to that of untreated cells, and U18 expression was used as an internal standard. The results showed that, in comparison to the control untreated groups, the mean levels of expression of both hsa-miR-125a-3p and hsa-miR-125a-5p in the sense groups were significantly increased ( $\mathrm{p}<0.001$ for both, Fig 6A and 6B).

We next analyzed the migratory capabilities of cells overexpressing hsa-miR-125a-3p/5p using transwell chambers. For analysis of hsa-miR-125a-3p, the number of A549 cells in the untreated group that migrated through a microporous membrane was $31.20 \pm 1.64$. There was no difference between untreated cells and cells transfected with the scramble-3p oligonucleotide (31.40 $\pm 0.55, \mathrm{p}=0.807$ ). However, the number of migrating cells 
Table 1: Relationship between hsa-miR-125a-3p expression and clinical pathological factors in lung cancinoma

\begin{tabular}{|c|c|c|c|c|}
\hline \multirow[b]{2}{*}{ Variable } & \multirow[b]{2}{*}{ Patients } & \multicolumn{3}{|c|}{ hsa-miR-125a-3p } \\
\hline & & Low expression(\%) & High expression(\%) & $p$ value \\
\hline \multicolumn{5}{|l|}{ Gender } \\
\hline Male & 33 & $12(36.4)$ & $21(63.6)$ & \\
\hline Female & 19 & $6(31.6)$ & $13(68.4)$ & $0.727^{b}$ \\
\hline \multicolumn{5}{|l|}{ Age } \\
\hline$\leq 60$ & 28 & $22(78.6)$ & $6(21.4)$ & \\
\hline$>60$ & 24 & $12(50.0)$ & $12(50.0)$ & $0.031^{b}$ \\
\hline \multicolumn{5}{|l|}{ Histology type } \\
\hline Squamous cancer & 22 & $13(59.1)$ & $9(40.9)$ & \\
\hline Adenocarcinoma & 30 & $21(70.0)$ & $9(30.0)$ & $0.414^{b}$ \\
\hline \multicolumn{5}{|l|}{ Pathological grade } \\
\hline I & 8 & $7(87.5)$ & $1(12.5)$ & \\
\hline II & 28 & $17(60.7)$ & $11(39.3)$ & \\
\hline III & 16 & $10(62.5)$ & $6(37.5)$ & $0.370^{c}$ \\
\hline \multicolumn{5}{|l|}{ Pathological stage } \\
\hline 1 & 18 & $8(44.4)$ & $10(55.6)$ & \\
\hline II & 15 & $10(66.7)$ & $5(33.3)$ & \\
\hline III & 19 & $16(80.0)$ & $3(20.0)$ & $0.012^{c}$ \\
\hline \multicolumn{5}{|l|}{ Lymph node status } \\
\hline No metastasis & 32 & $17(53.1)$ & $15(46.9)$ & \\
\hline Metastasis & 20 & $17(85.0)$ & $3(15.0)$ & $0.034^{a}$ \\
\hline
\end{tabular}

a Two-sided Fisher's Exact Test.

b Chi-square Test

cMann-whitney Test

was significantly decreased when cells were transfected with the sense-3p oligonucleotide $(16.40 \pm 2.07, \mathrm{p}<$ 0.001 ). For hsa-miR-125a-5p, the number of SPC-A-1 cells in the untreated group that migrated through the microporous membrane was $26.60 \pm 2.07$. Again no difference was observed between untreated cells and cells transfected with the scramble-5p oligonucleotide $(25.60$ $\pm 1.67, \mathrm{p}=0.426$ ). However, the number of migrating cells increased significantly when cells were transfected with the sense-5p oligonucleotide (38.80 \pm 1.92 , p $<0.001$, Fig 7).

In the hsa-miR-125a-3p invasion analysis, the number of A549 cells in the untreated group that invaded through the Matrigel was $24.40 \pm 2.41$. There was no difference between untreated cells and cells transfected with the scramble-3p oligonucleotide $(24.80 \pm 3.03, \mathrm{p}=0.823)$. The number of invading cells decreased significantly when cells were transfected with the sense-3p oligonucleotide $(12.20 \pm 1.58, \mathrm{p}<0.001)$. In the invasion assay for hsa-miR-125a-5p, the number of SPC-A-1 cells in the untreated group that invaded through the Matrigel was $22.20 \pm 1.72$. Again no significant difference was observed between untreated cells and cells transfected with the scramble-5p oligonucleotide $(23.40 \pm 2.34, \mathrm{p}=$ 1.000). However, the number of invading cells increased significantly when cells were transfected with the sense5 p oligonucleotide $(30.80 \pm 1.92, \mathrm{p}<0.001$, Fig 7$)$.

\section{Effects loss-of-function of hsa-miR-125a-3p/5p on the migratory and invasive capabilities of A549 and SPC-A-1 cells}

To further examine whether endogenous hsa-miR-125a$3 p$ and hsa-miR-125a-5p regulate migration and invasion, we adopted a loss-of-function approach that blocked the function of endogenous hsa-miR-125a-3p and hsa-miR125a-5p using antisense 2'-O-methyl oligonucleotides [23-26]. We then analyzed the migratory and invasive capabilities of these cells using the methods described above. In the hsa-miR-125a-3p migration assay, the number of A549 cells in the untreated group that migrated 
Table 2: Relationship between hsa-miR-125a-5p expression and clinical pathological factors in lung cancinoma

\begin{tabular}{|c|c|c|c|c|}
\hline \multirow[b]{2}{*}{ Variable } & \multirow[b]{2}{*}{ Patients } & \multicolumn{3}{|c|}{ hsa-miR-125a-5p } \\
\hline & & Low expression(\%) & High expression(\%) & $p$ value \\
\hline \multicolumn{5}{|l|}{ Gender } \\
\hline Male & 33 & $14(42.4)$ & $19(57.6)$ & \\
\hline Female & 19 & $6(31.6)$ & $13(68.4)$ & $0.439^{b}$ \\
\hline \multicolumn{5}{|l|}{ Age } \\
\hline$\leq 60$ & 28 & $11(39.3)$ & $17(60.7)$ & \\
\hline$>60$ & 24 & $9(37.5)$ & $15(62.5)$ & $1.000^{\mathrm{b}}$ \\
\hline \multicolumn{5}{|l|}{ Histology type } \\
\hline Squamous cancer & 22 & $9(40.9)$ & $13(59.1)$ & \\
\hline Adenocarcinoma & 30 & $11(36.7)$ & $19(63.3)$ & $0.780^{\mathrm{b}}$ \\
\hline \multicolumn{5}{|l|}{ Pathological grade } \\
\hline I & 8 & $4(50.0)$ & $4(50.0)$ & \\
\hline II & 28 & $11(39.3)$ & $17(60.7)$ & \\
\hline III & 16 & $5(31.3)$ & $11(68.7)$ & $0.380^{c}$ \\
\hline \multicolumn{5}{|l|}{ Pathological stage } \\
\hline 1 & 18 & $12(66.7)$ & $6(33.3)$ & \\
\hline II & 15 & $5(33.3)$ & $10(66.7)$ & \\
\hline III & 19 & $3(15.8)$ & $16(84.2)$ & $0.002^{c}$ \\
\hline \multicolumn{5}{|l|}{ Lymph node status } \\
\hline No metastasis & 32 & $16(50.0)$ & $16(50.0)$ & \\
\hline Metastasis & 20 & $4(20.0)$ & $16(80.0)$ & $0.042^{\mathrm{a}}$ \\
\hline
\end{tabular}

a Two-sided Fisher's Exact Test.

bChi-square Test

cMann-whitney Test

through the microporous membrane was $31.00 \pm 1.54$. There was no difference between the untreated and scramble-3p-transfected cells $(32.00 \pm 0.58, \mathrm{p}=0.347)$. The number of migrating cells was significantly increased when A549 cells were transfected with the antisense-3p oligonucleotide $(46.00 \pm 3.16, \mathrm{p}<0.001)$. For the hsamiR-125a-5p migration assay, the number of SPC-A-1 cells in the untreated group that migrated through the microporous membrane was $22.60 \pm 2.07$. No difference was observed between untreated and scramble-5p-transfected cells $(22.40 \pm 1.14, \mathrm{p}=0.855)$. The number of migrating cells was significantly decreased when SPC-A1 cells were transfected with the antisense-5p oligonucleotide $(15.00 \pm 1.58, \mathrm{p}<0.001$, Fig 8$)$.

In the hsa-miR-125a-3p invasion assay, the number of A549 cells in the untreated group that invaded through the Matrigel was $25.00 \pm 1.51$. There was no difference between untreated and scramble-3p-transfected cells $(24.60 \pm 3.04, \mathrm{p}=0.801)$. The number of invading cells was significantly increased when A549 cells were trans- fected with the antisense-3p oligonucleotide (37.00 \pm $2.73, \mathrm{p}<0.001)$. In the hsa-miR-125a-5p invasion assay, the number of SPC-A-1 cells in the untreated group that invaded through the Matrigel was $21.00 \pm 1.59$. No significant difference was observed between untreated and scramble-5p-transfected cells $(20.80 \pm 0.84, \mathrm{p}=0.809)$. The number of invading SPC-A-1 cells decreased significantly when cells were transfected with the antisense-5p oligonucleotide (11.00 $\pm 1.07, \mathrm{p}<0.001$, Fig 8$)$.

\section{Discussion}

MiRNAs have emerged as important regulators of tumorigenesis $[27,28]$. Mounting evidence has shown that miRNAs are frequently mutated or differentially expressed in human cancers, suggesting that miRNAs may act as tumor suppressors or oncogenes depending on whether their specific targets act as oncogenes or tumor suppressors [29]. Therefore, tumor suppressor miRNAs are generally expressed at low levels $[30,31]$ and oncogenic miRNAs are expressed at high levels in tumors or 

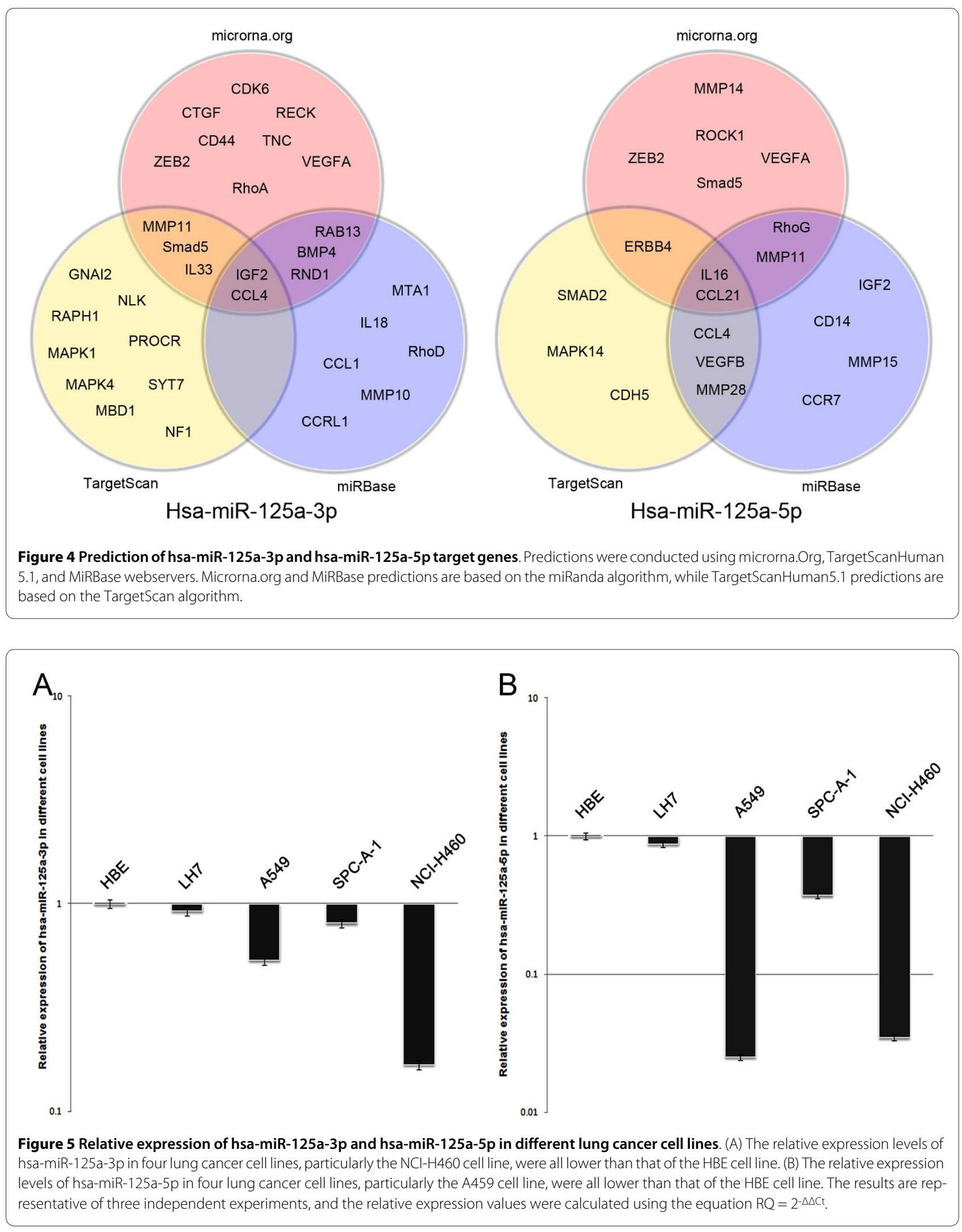

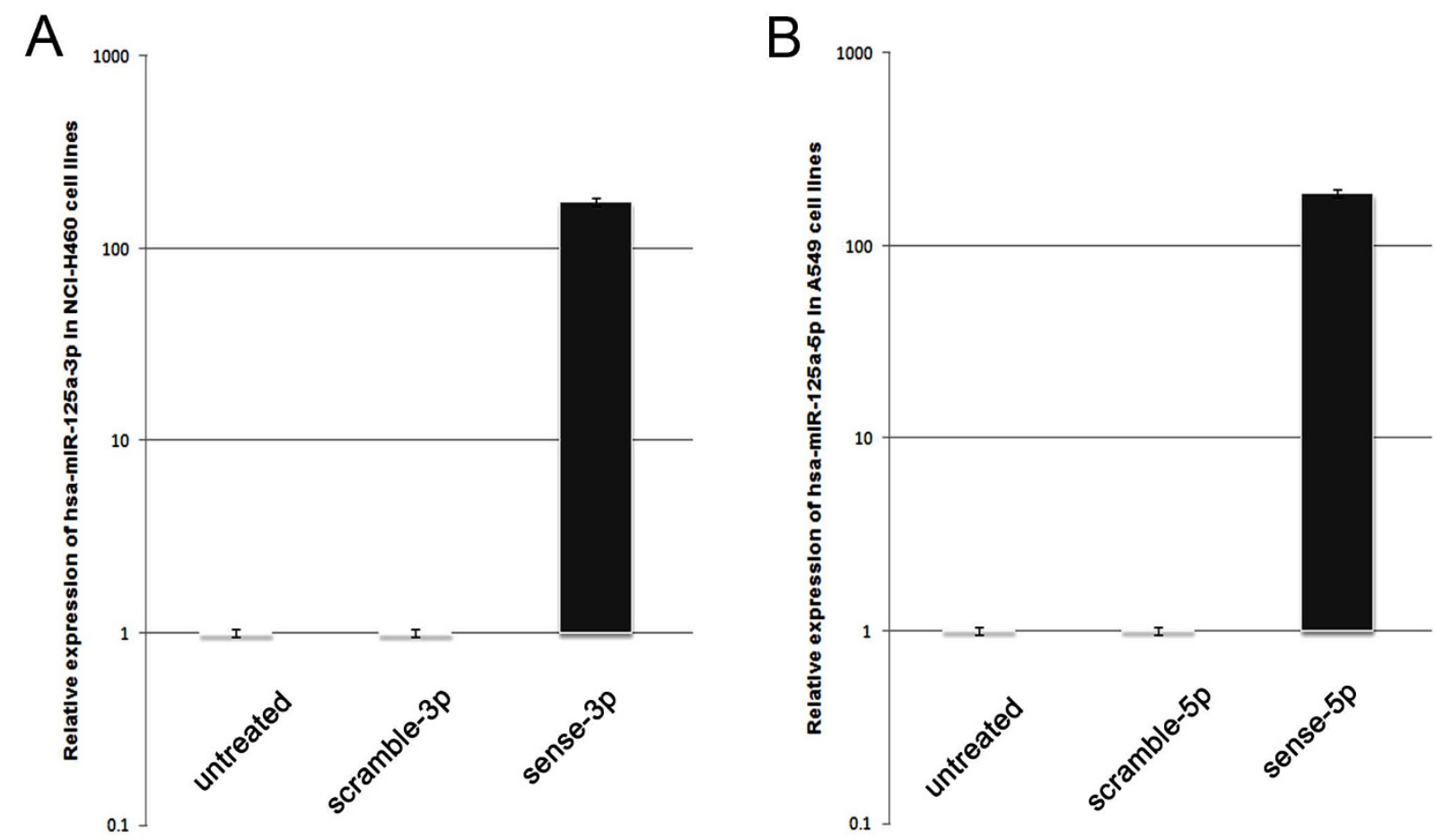

Figure 6 Relative levels of hsa-miR-125a-3p and hsa-miR-125a-5p were increased by transfection with sense 2'-0-methyl oligonucleotides. (A) The relative levels of hsa-miR-125a-3p were significantly increased in the sense-3p-transfected group. (B) The relative levels of hsa-miR-125a-5p were significantly increased in the sense- $5 \mathrm{p}$-transfected group. The results are representative of three independent experiments, and the relative expression values were calculated using the equation $R Q=2^{-\Delta \Delta C t}$.

tumor cell lines [32,33]. These observations suggest that specific characterization of miRNA expression and function could lead to the identification of novel biomarkers to predict clinical outcomes in the future [34-37].

In the present study, we report that expression of hsamiR-125a-3p and hsa-miR-125a-5p is dysregulated in lung cancer. Consistent with the results of Yanainhara [20], real-time PCR results showed that expression of hsa-miR-125a-5p was decreased significantly in the majority of NSCLCs in comparison to matched LACs. In addition, we also found that expression of hsa-miR-125a$3 p$ was significantly reduced. This expression pattern suggests that hsa-miR-125a-3p and hsa-miR-125a-5p may act as tumor suppressors by regulating expression of a subset of oncogenes. These specific alterations in expression may be characteristic of human lung cancer and may contribute to lung tumorigenesis.

Tumor invasion and metastasis are the most common cause of cancer deaths worldwide [38,39]. Studies regarding the functions of miRNAs in tumor invasion and metastasis currently represent a major focus in cancer biology $[14,40]$. In this study, we evaluated the correlation between hsa-miR-125a-3p/5p expression levels and clinicopathological variables in 52 NSCLC tissues. Interestingly, we found that hsa-miR-125a-3p/5p expression levels were correlated with pathological stage and lymph node metastasis. Together with our functional studies in lung cancer cells, these results suggest that hsa-miR$125 a-3 p$ and hsa-miR-125a-5p function in opposite manners to suppress and enhance cell migration and invasion of lung cancer cells, respectively, which may in turn affect lymph node metastasis in NSCLC.

The specific mechanisms that lead to changes in cell migration and invasion regulated by hsa-miR-125a-3p/5p in lung cancer cells remain unknown. MiRNAs are commonly thought to posttranscriptionally regulate mRNA degradation and inhibition of mRNA translation via interactions with the 3'-untranslated regions (UTRs) of target mRNAs in animals [16-18]. However, there are several remaining gaps in our knowledge of miRNA function that have been revealed by recent studies. Recently, a few experiments have indicated possible target sites in the 5'UTR of mRNAs [41]. Furthermore, 0rom and colleagues [7] found that miRNA-10a binds the 5'UTR of ribosomal protein mRNAs and enhances their translation. Therefore, the regulatory mechanisms controlled by miRNAs are may be more varied and extensive than previously thought.

According to predicted results from three webserver databases, CCL4 and IGF-2 were the most likely target 

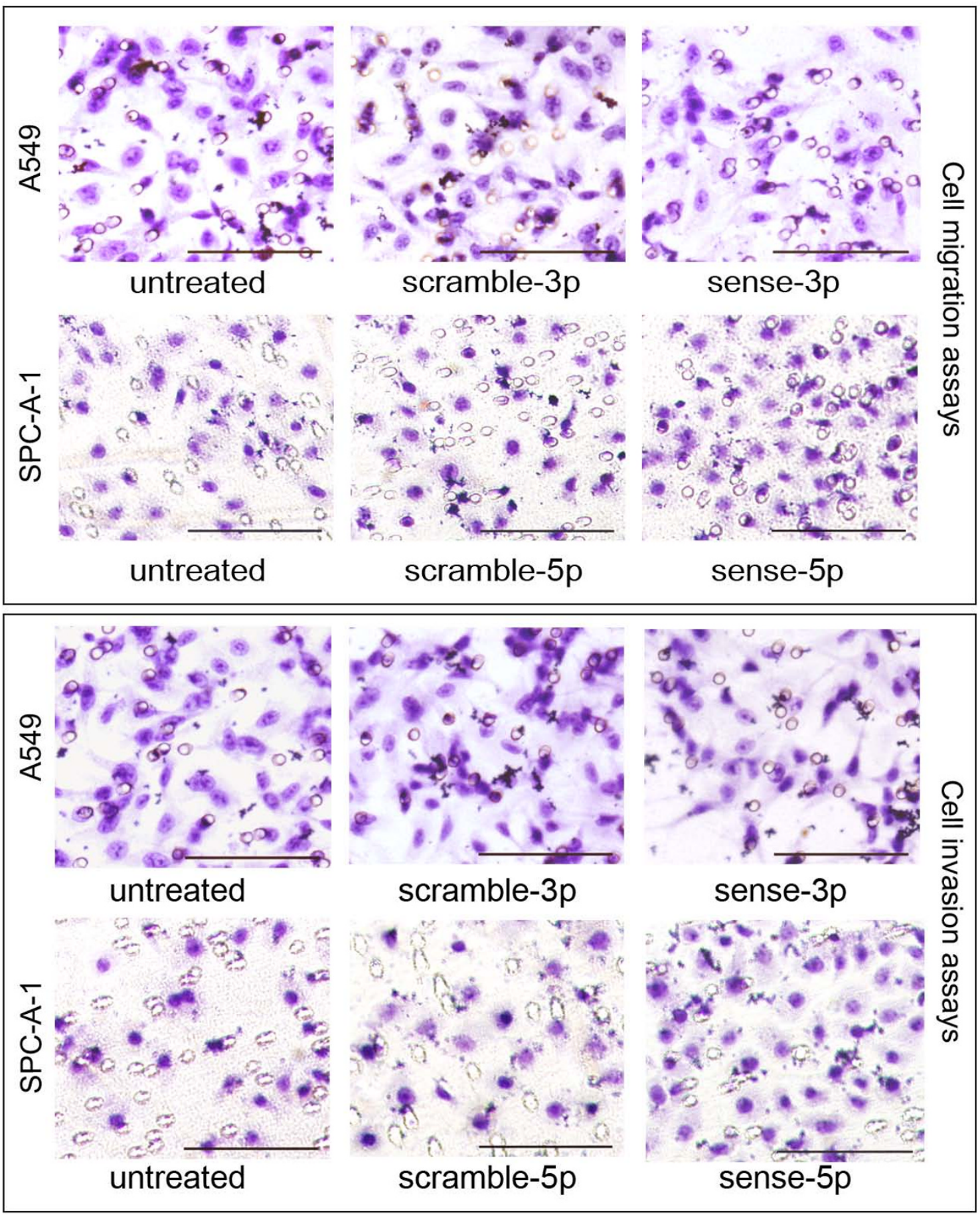

Figure 7 Effects of gain-of-function of hsa-miR-125a-3p/5p on migration and invasion of lung cancer cells. Migration assay results showed that the number of A549 cells that migrated through the microporous membrane was significantly decreased in the sense-3p group ( $p<0.001$ ). In contrast, the number of migratory SPC-A-1 cells was significantly increased in the sense-5p group ( $p<0.001$, bar $=20 \mu m)$. Invasion assay results showed that the number of A549 cells that invaded through the Matrigel was significantly decreased in the sense-3p group ( $p<0.001)$. However, the number of invasive SPC-A-1 cells significantly increased in the sense-5p group $(p<0.001, b a r=20 \mu \mathrm{m})$. The results are representative of three independent experiments. 

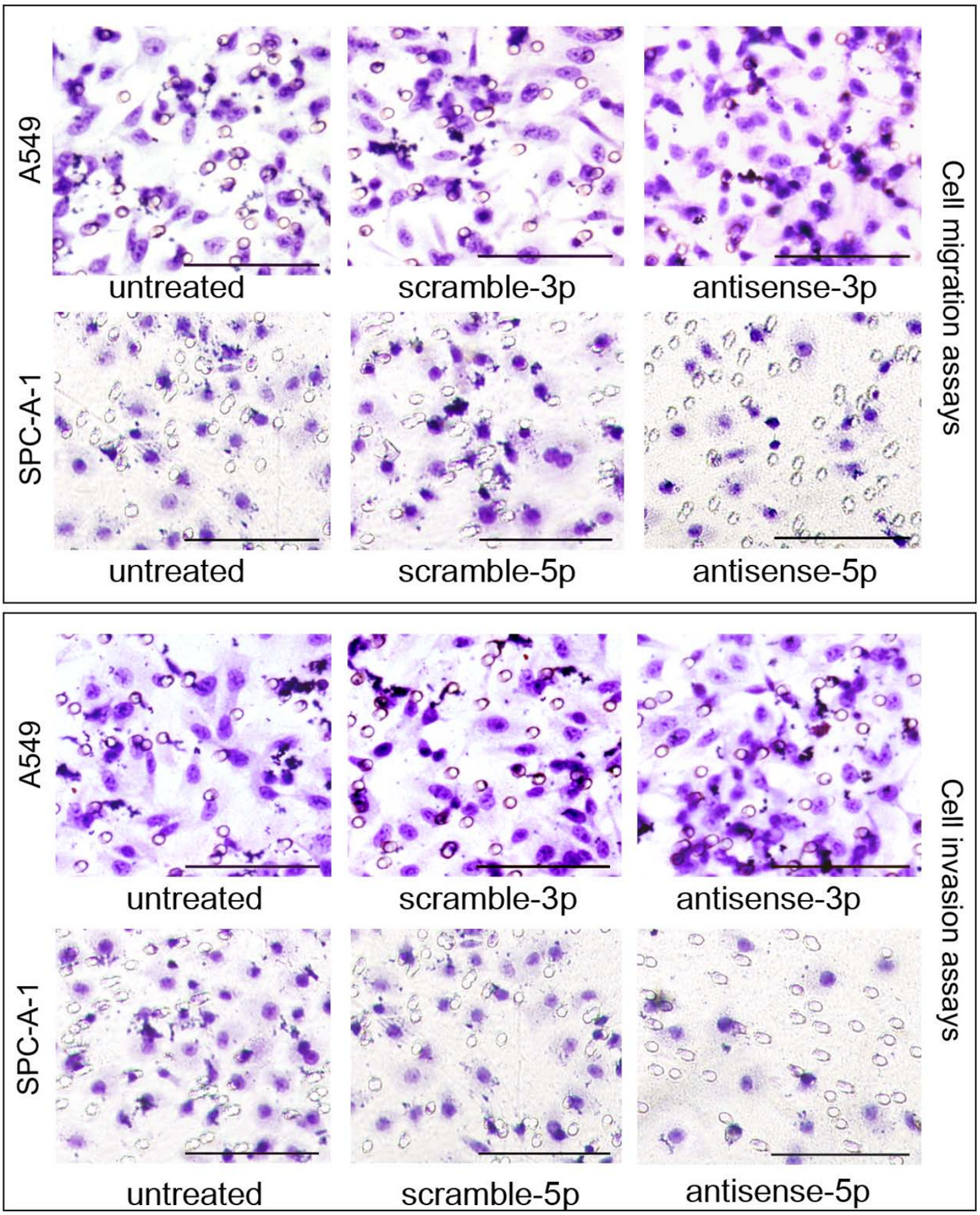

Figure 8 Effects of loss-of-function of hsa-miR-125a-3p/5p on migration and invasion of lung cancer cells. Migration assay results showed that the number of A549 cells that migrated through the microporous membrane was significantly increased in the antisense-3p group ( $p<0.001)$. However, the number of migratory SPC-A-1 cells was significantly decreased in the antisense-5p group $(p<0.001$, bar $=20 \mu m)$. Invasion assay results showed that the number of A549 cells that invaded through the Matrigel was significantly increased in the antisense-3p group ( $p<0.001$ ). In contrast, the number of invasive SPC-A-1 cells was significantly decreased in the antisense-5p group $(p<0.001$, bar $=20 \mu m)$. The results are representative of three independent experiments. 
genes of hsa-miR-125a-3p, while IL16 and CCL21 were the most likely target genes of hsa-miR-125a-5p. CCL4 (MIP-1beta), a member of the CC chemokine family, induces cellular migration and invasion through interactions with its receptor CCR5 [42,43]. Nussbaum and colleagues [44] have reported that IGF-2 and its receptor IGF-2R stimulate tumor cell migration in human hepatocarcinogenesis. IL-16, an activator of the plasminogenplasmin system, promotes human eosinophil migration into the extracellular matrix via a CCR3-chemokinemediated signaling pathway [45]. Previous results from our laboratory indicated that CCR7 and its ligand CCL21 regulate migration and invasion of lung cancer cells through the ERK1/2 pathway under hypoxic conditions and promote metastasis of lung cancer [46]. Therefore, the complicated regulatory mechanisms controlled by hsa-miR-125a-3p and hsa-miR-125a-5p may play complex roles in migration and invasion. Despite the necessity for further studies to understand these mechanisms, our findings suggest a crucial role for miR-125a in lung cancer.

\section{Conclusion}

The results from this study demonstrate that hsa-miR125a-3p and hsa-miR-125a-5p, two miRNAs that are downregulated in NSCLC, are associated with lymph node metastasis. In vitro functional studies in lung cancer cells revealed that hsa-miR-125a-3p and hsa-miR-125a$5 p$ appear to play opposite cellular roles, suppressing and enhancing cell migration and invasion, respectively. Thus, these results may lead to the identification of novel biomarkers and therapeutic strategies to combat lymph node metastasis.

\section{Additional material}

Additional file 1 The specificity and sensitivity of hsa-miR-125a-3p and hsa-miR-125a-5p. (A) The specificity and sensitivity of hsa-miR-125a$3 p$ was analyzed by DOC Curve. (B) The specificity and sensitivity of hsamiR-125a-5p was analyzed by DOC Curve.

Additional file 2 Prediction of target sites for hsa-miR-125a-3p and target mRNAs in three databases. The target sites for hsa-miR-125a-3p and the target mRNAs were predicted using microrna.org, TargetScanHuman 5.1 and MiRBase webservers to further illustrate results shown in Fig. 4.

Additional file 3 Prediction of target sites for hsa-miR-125a-5p and target mRNAs in three databases. The target sites of hsa-miR-125a-5p and the target mRNAs were predicted using microrna.org, TargetScanHuman 5.1 and MiRBase webservers to further illustrate results shown in Fig. 4.

Additional file 4 Details of the target genes of hsa-miR-125a-3p Details of the target genes of hsa-miR-125a-3p.

Additional file 5 Details of the target genes of hsa-miR-125a-5p Details of the target genes of hsa-miR-125a-5p.

\section{Competing interests}

The authors declare that they have no competing interests.

\section{Authors' contributions}

$\sqcup$ initiated the research, carried out the experiments, and wrote the manuscript. QH and SZ contributed to translation of the paper. QZ and JC provided experimental instruction. $\mathrm{XQ}$ helped with the experimental design and provided funding support. EW provided critical review of the manuscript. All authors read and approved the final manuscript.

\section{Acknowledgements}

We are very grateful to Dr. Baoshen Zhou from the Department of Epidemiology, School of Public Health, China Medical University for statistical analysis. We are also grateful to the members of our laboratory for useful suggestions.

\section{Author Details}

'Department of Pathology, the First Affiliated Hospital of China Medical University, No. 92 North Second Road, Heping District, Shenyang, Liaoning 110001, China, ${ }^{2}$ Department of Pathology, College of Basic Medical Sciences, China Medical University, No. 92 North Second Road, Heping District, Shenyang, Liaoning 110001, China and ${ }^{3}$ Center of Laboratory Technology and Experimental Medicine, China Medical University, No. 92 North Second Road, Heping District, Shenyang, Liaoning 110001, China

Received: 24 November 2009 Accepted: 22 June 2010

Published: 22 June 2010

\section{References}

1. Lee RC, Feinbaum RL, Ambros V: The C. elegans heterochronic gene lin-4 encodes small RNAs with antisense complementarity to lin-14. Cell 1993, 75:843-54.

2. Lee Y, Ahn C, Han J, Choi H, Kim J, Yim J, Lee J, Provost P, Rådmark O, Kim S, Kim VN: The nuclear RNase III Drosha initiates microRNA processing. Nature 2003, 425:415-9.

3. Kong W, Zhao JJ, He L, Cheng JQ: Strategies for profiling microRNA expression. J Cell Physiol 2009, 218:22-5.

4. Hutvágner G, McLachlan J, Pasquinelli AE, Bálint E, Tuschl T, Zamore PD: A cellular function for the RNA-interference enzyme Dicer in the maturation of the let-7 small temporal RNA. Science 2001, 293:834-8.

5. Grishok A, Pasquinelli AE, Conte D, Li N, Parrish S, Ha I, Baillie DL, Fire A, Ruvkun G, Mello CC: Genes and mechanisms related to RNA interference regulate expression of the small temporal RNAs that control C. elegans developmental timing. Cell 2001, 106:23-34.

6. Schwarz DS, Hutvágner G, Du T, Xu Z, Aronin N, Zamore PD: Asymmetry in the assembly of the RNAi enzyme complex. Cell 2003, 115:199-208.

7. Ørom UA, Nielsen FC, Lund AH: MicroRNA-10a binds the 5'UTR of ribosomal protein mRNAs and enhances their translation. $\mathrm{Mol}$ Cell 2008, 30:460-71.

8. Brennecke J, Stark A, Russell RB, Cohen SM: Principles of microRNA-target recognition. PLOS Biol 2005, 3:e85.

9. Bartel DP: MicroRNAs genomics, biogenesis, mechanism, and function. Cell 2004, 116:281-297.

10. Calin GA, Sevignani C, Dumitru CD, Hyslop T, Noch E, Yendamuri S, Shimizu M, Rattan S, Bullrich F, Negrini M, Croce CM: Human microRNA genes are frequently located at fragile sites and genomic regions involved in cancers. Proc Natl Acad Sci USA 2004, 101:2999-3004.

11. Crawford M, Brawner E, Batte K, Yu L, Hunter MG, Otterson GA, Nuovo G, Marsh CB, Nana-Sinkam SP: MicroRNA-126 inhibits invasion in nonsmall cell lung carcinoma cell lines. Biochem Biophys Res Commun 2008, 373:607-12.

12. Zhu S, Wu H, Wu F, Nie D, Sheng S, Mo YY: MicroRNA-21 targets tumor suppressor genes in invasion and metastasis. Cell Res 2008, 18:350-9.

13. Tavazoie SF, Alarcón C, Oskarsson T, Padua D, Wang Q, Bos PD, Gerald WL, Massagué J: Endogenous human microRNAs that suppress breast cancer metastasis. Nature 2008, 451:147-52.

14. Nicoloso MS, Spizzo R, Shimizu M, Rossi S, Calin GA: MicroRNAs -- the micro steering wheel of tumour metastases. Nat Rev Cancer 2009, 9:293-302.

15. Valastyan S, Reinhardt F, Benaich N, Calogrias D, Szász AM, Wang ZC, Brock JE, Richardson AL, Weinberg RA: A pleiotropically acting microRNA miR31, inhibits breast cancer metastasis. Cell 2009, 137:1032-46.

16. Kong W, Yang H, He L, Zhao JJ, Coppola D, Dalton WS, Cheng JQ: MicroRNA-155 is regulated by the transforming growth factor beta/ Smad pathway and contributes to epithelial cell plasticity by targeting RhoA. Mol Cell Biol 2008, 28:6773-84.

17. Asangani IA, Rasheed SA, Nikolova DA, Leupold JH, Colburn NH, Post S, Allgayer H: MicroRNA-21 (miR-21) posttranscriptionally downregulates 
tumor suppressor Pdcd4 and stimulates invasion, intravasation and metastasis in colorectal cancer. Oncogene 2008, 27:2128-2136.

18. Gabriely G, Wurdinger T, Kesari S, Esau CC, Burchard J, Linsley PS, Krichevsky AM: MicroRNA 21 promotes glioma invasion by targeting matrix metalloproteinase regulators. Mol Cell Biol 2008, 28:5369-5380.

19. Yang J, Mani SA, Weinberg RA: Exploring a new twist on tumor metastasis. Cancer Res 2006, 66:4549-4552.

20. Yanaihara N, Caplen N, Bowman E, Seike M, Kumamoto K, Yi M, Stephens RM, Okamoto A, Yokota J, Tanaka T, Calin GA, Liu CG, Croce CM, Harris CC: Unique microRNA molecular profiles in lung cancer diagnosis and prognosis. Cancer Cell 2006, 9:189-98.

21. Agresti Alan: A Survey of Exact Inference for Contingency Tables. Statistical Science 1992, 7:131-177.

22. Yan LX, Huang XF, Shao Q, Huang MY, Deng L, Wu QL, Zeng YX, Shao JY: MicroRNA miR-21 overexpression in human breast cancer is associated with advanced clinical stage, lymph node metastasis and patient poor prognosis. RNA 2008, 14:2348-60.

23. Séguin RM, Ferrari N: Emerging oligonucleotide therapies for asthma and chronic obstructive pulmonary disease. Expert Opin InvestigDrugs 2009, 18:1505-17.

24. Cheng AM, Byrom MW, Shelton J, Ford LP: Antisense inhibition of human miRNAs and indications for an involvement of miRNA in cell growth and apoptosis. Nucleic Acids Res 2005, 33:1290-1297.

25. O'Donnell KA, Wentzel EA, Zeller Kl, Dang CV, Mendell JT: c-Mycregulated microRNAs modulate E2F1 expression. Nature 2005, 435:839-843.

26. Fabani MM, Gait MJ: miR-122 targeting with LNA/2C-O-methyl oligonucleotide mixmers, peptide nucleic acids (PNA), and PNA peptide conjugates. RNA 2008, 14:336-346.

27. Chen HC, Chen GH, Chen YH, Liao WL, Liu CY, Chang KP, Chang YS, Chen $\mathrm{SJ}$ : MicroRNA deregulation and pathway alterations in nasopharyngeal carcinoma. Br J Cancer 2009, 100:1002-11.

28. Deng S, Calin GA, Croce CM, Coukos G, Zhang L: Mechanisms of microRNA deregulation in human cancer. Cell Cycle 2008, 7:2643-6.

29. Zhang B, Pan X, Cobb GP, Anderson TA: microRNAs as oncogenes and tumor suppressors. Dev Biol 2007, 302:1-12.

30. Inamura K, Togashi $Y$, Nomura K, Ninomiya H, Hiramatsu M, Satoh Y, Okumura S, Nakagawa K, Ishikawa Y: let-7 microRNA expression is reduced in bronchioloalveolar carcinoma, a non-invasive carcinoma, and is not correlated with prognosis. Lung Cancer 2007, 58:392-6.

31. Calin GA, Cimmino A, Fabbri M, Ferracin M, Wojcik SE, Shimizu M, Taccioli C, Zanesi N, Garzon R, Ageilan Rl, Alder H, Volinia S, Rassenti L, Liu X, Liu CG, Kipps TJ, Negrini M, Croce CM: MiR-15a and miR-16-1 cluster functions in human leukemia. Proc Natl Acad Sci USA 2008, 105:5166-71.

32. Markou A, Tsaroucha EG, Kaklamanis L, Fotinou M, Georgoulias V, Lianidou ES: Prognostic value of mature microRNA-21 and microRNA-205 overexpression in non-small cell lung cancer by quantitative real-time RT-PCR. Clin Chem 2008, 4:1696-704.

33. Eis PS, Tam W, Sun L, Chadburn A, Li Z, Gomez MF, Lund E, Dahlberg JE: Accumulation of miR-155 and BIC RNA in human $B$ cell lymphomas. Proc Natl Acad Sci USA 2005, 102:3627-32.

34. Habbe N, Koorstra JB, Mendell JT, Offerhaus GJ, Ryu JK, Feldmann G, Mullendore ME, Goggins MG, Hong SM, Maitra A: MicroRNA miR-155 is a biomarker of early pancreatic neoplasia. Cancer Biol Ther 2009, 8:340-6.

35. Caldas C, Brenton JD: Sizing up miRNAs as cancer genes. Nat Med 2005, 11:712-714

36. Iorio MV, Casalini P, Tagliabue E, Ménard S, Croce CM: MicroRNA profiling as a tool to understand prognosis, therapy response and resistance in breast cancer. Eur J Cancer 2008, 44:2753-9.

37. Tavazoie SF, Alarcón C, Oskarsson T, Padua D, Wang Q, Bos PD, Gerald WL, Massagué J: Endogenous human microRNAs that suppress breast cancer metastasis. Nature 2008, 451:147-52

38. Geiger TR, Peeper DS: Metastasis mechanisms. Biochim BiophysActa 2009, 1796:293-308

39. Hedley BD, Chambers AF: Tumor dormancy and metastasis. Adv Cancer Res 2009, 102:67-101.

40. Ma L, Weinberg RA: Micromanagers of malignancy: role of microRNAs in regulating metastasis. Trends Genet 2008, 24:448-56

41. Lee I, Ajay SS, Yook JI, Kim HS, Hong SH, Kim NH, Dhanasekaran SM, Chinnaiyan AM, Athey BD: New class of microRNA targets containing simultaneous 5'-UTR and 3'-UTR interaction sites. Genome Res 2009, 19:1175-83
42. Menten P, Saccani A, Dillen C, Wuyts A, Struyf S, Proost P, Mantovani A Wang JM, Van Damme J: Role of the autocrine chemokines MIP-1alpha and MIP-1 beta in the metastatic behavior of murine T cell lymphoma. $J$ Leukoc Biol 2002, 72:780-9.

43. Van Deventer HW, Wu QP, Bergstralh DT, Davis BK, O'Connor BP, Ting JP, Serody JS: C-C chemokine receptor 5 on pulmonary fibrocytes facilitates migration and promotes metastasis via matrix metalloproteinase 9. Am J Pathol 2008, 173:253-64.

44. Nussbaum T, Samarin J, Ehemann V, Bissinger M, Ryschich E, Khamidjanov A, Yu X, Gretz N, Schirmacher P, Breuhahn K: Autocrine insulin-like growth factor-II stimulation of tumor cell migration is a progression step in human hepatocarcinogenesis. Hepatology 2008, 48:146-56.

45. Ferland C, Flamand N, Davoine F, Chakir J, Laviolette M: IL-16 Activates Plasminogen-Plasmin System and Promotes Human Eosinophil Migration into Extracellular Matrix via CCR3-Chemokine-Mediated Signaling and by Modulating CD4 Eosinophil Expression. J Immunol 2004, 173:4417-24.

46. Li Y, Qiu X, Zhang S, Zhang Q, Wang E: Hypoxia induced CCR7 expression via HIF-1alpha and HIF-2alpha correlates with migration and invasion in lung cancer cells. Cancer Biol Ther 2009, 8:322-30.

\section{Pre-publication history}

The pre-publication history for this paper can be accessed here: http://www.biomedcentral.com/1471-2407/10/318/prepub

doi: $10.1186 / 1471-2407-10-318$

Cite this article as: Jiang et al., Hsa-miR-125a-3p and hsa-miR-125a-5p are downregulated in non-small cell lung cancer and have inverse effects on invasion and migration of lung cancer cells BMC Cancer 2010, 10:318

\section{Submit your next manuscript to BioMed Central and take full advantage of:}

- Convenient online submission

- Thorough peer review

- No space constraints or color figure charges

- Immediate publication on acceptance

- Inclusion in PubMed, CAS, Scopus and Google Scholar

- Research which is freely available for redistribution

Submit your manuscript at www.biomedcentral.com/submit
C Biomed Central 